\title{
DETERMINATION OF THE SOURCE AND THE MEANS OF PREVENTION OF STONES IN GLASS
}

\author{
By Herbert Insley
}

\section{ABSTRACT}

The miscroscopic characteristics of different crystalline materials occurring as stones or lumps in glass are described and photomicrographs of stones originating from devitrification of the glass, incomplete solution of batch constituents, and incorporation in the glass of refractory wall material are reproduced. Methods of determining the location in the glass-making system of the source of stones, using microscopic as well as other methods, are given. Means of prevention or elimination of the stones are suggested.

\section{CONTENTS}

I. Introduction 1077

II. Devitrification stones_.

III. Batch stones _.

IV. Refractory stones.

V. Summary

\section{INTRODUCTION}

In glass, "stones" are segregations of undissolved or crystallized material. The petrographic microscope has been found to be the only instrument which is generally useful in identifying the crystalline compounds in these stones. The optical constants, the general types, and the methods of identification of stones in glass have been reported in previous papers. ${ }^{1}$ It is the purpose of this paper to show how the nature of the crystal assemblages, the shape and size of the crystals, and the amount of reaction between the stones and the molten glass indicate in what manner and from what material sources these stones originate and where in the glass-making operations they first appear. Possible methods for the prevention of different types of stones will also be discussed.

According to their source stones may be of three types-devitrification stones, batch stones, and refractory stones. Devitrification stones are the result of the crystallization of one or more of the constituents of the glass itself. Batch stones are due to the incomplete solution in the molten glass of one of the constituents of the batch. Refractory stones have their source in the walls of the pot or tank and they are introduced into the melt by spalling or by selective solution of the refractories.

${ }^{1}$ N. L. Bowen, J. Am. Cer. Soc., 1, pp. 594-605; 1918. Herbert Insley, J. Am. Cer. Soc., 6, pp. 706$716 ; 1923 ; 7$, pp. 14-18; 1924. 


\section{DEVITRIFICATION STONES}

Crystallization in the glass, resulting in devitrification stones, is caused by improper batch compositions, improper temperatures in those stages of the manufacturing process where crystallization takes place, or by nonuniformities of composition within the melt. The local composition and temperature determine, of course, what compound, if any, will crystallize at any given point in the melt.

The accompanying photomicrographs of sections of devitrification stones (figs. 1, 2, 3, 4, and 5) show the different structures which are characteristic of the compounds crystallizing and of the conditions under which crystallization takes place. Figure 1 is a portion of a spherical group of minute tridymite $\left(\mathrm{SiO}_{2}\right)$ crystals. Many of these spherical aggregates-each from 1 to $2 \mathrm{~cm}$ in diameter-were formed in a random arrangement in a mass of glass which had lain for several days in the flow spout of a bottle glass tank at an estimated maximum temperature between $1,100^{\circ}$ and $1,200^{\circ} \mathrm{C}$. Evidently crystallization in this case can be ascribed to the long heat treatment to which the glass was subjected.

Figure 2 shows a thin section of wollastonite $\left(\mathrm{CaO} . \mathrm{SiO}_{2}\right)$ "dog" taken from the bottom of a sheet-glass tank after the tank was shut down for repairs. The laminated appearance. was produced by a series of fine threads which are composed of innumerable minute crystals of wollastonite. This structure indicates that crystallization was fairly rapid.

Figure 3 is a photomicrograph of a section of scum removed with a ladle from the melting surface of a sheet-glass tank. Dolomitic limestone was used in the batch, and, consequently, the crystals formed were diopside $\left(\mathrm{CaO} \cdot \mathrm{MgO} \cdot 2 \mathrm{SiO}_{2}\right)$ instead of wollastonite $\left(\mathrm{CaO} . \mathrm{SiO}_{2}\right)$, the related compound which may crystallize when nonmagnesian limestone is used.

The compound $\mathrm{Na}_{2} \mathrm{O} .3 \mathrm{CaO} .6 \mathrm{SiO}_{2}$ has been found in several instances in plate and sheet glass. It may occur as large masses in the bottom of the tank or as individual crystals scattered through the finished sheet. Figure 4 shows a section taken from a mass of this material collected from the bottom of a tank. The radiating, feathery habit indicates either that crystallization was rapid or that the glass was unusually viscous.

In a glass used for making amber glass tubing with an automatic machine, a crystalline material was formed which appeared in the tubing as clots. A microscopic examination of this material showed it to be Jeffersonite (fig. 5), a compound related to diopside but which contains varying amounts of zinc and manganese. The glass itself contained oxides of iron, zinc, manganese, and magnesium as well as the customary soda, lime, and silica.

The detection of the place in the manufacturing process at which crystallization first occurs is of great importance in determining what 


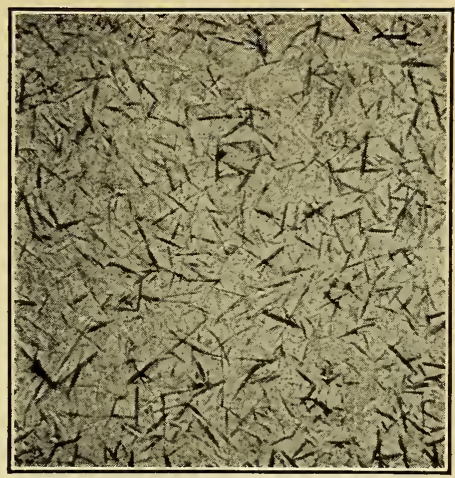

Figure 1.-Hexagonal plates of tridymite (turned on edge) embedded in bottle glass

Magnification $\times 50$. Ordinary light.

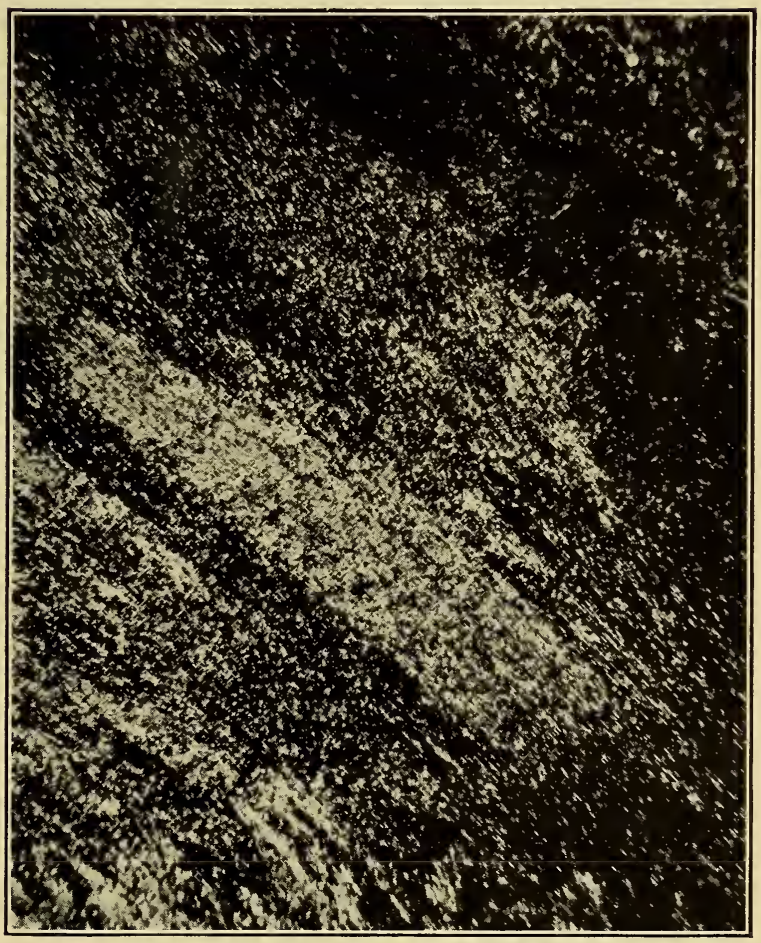

Figure 2.-Section of a mass of wollastonite crystals from the bottom of a tank

Magnification $\times 35$. Nicols crossed. 


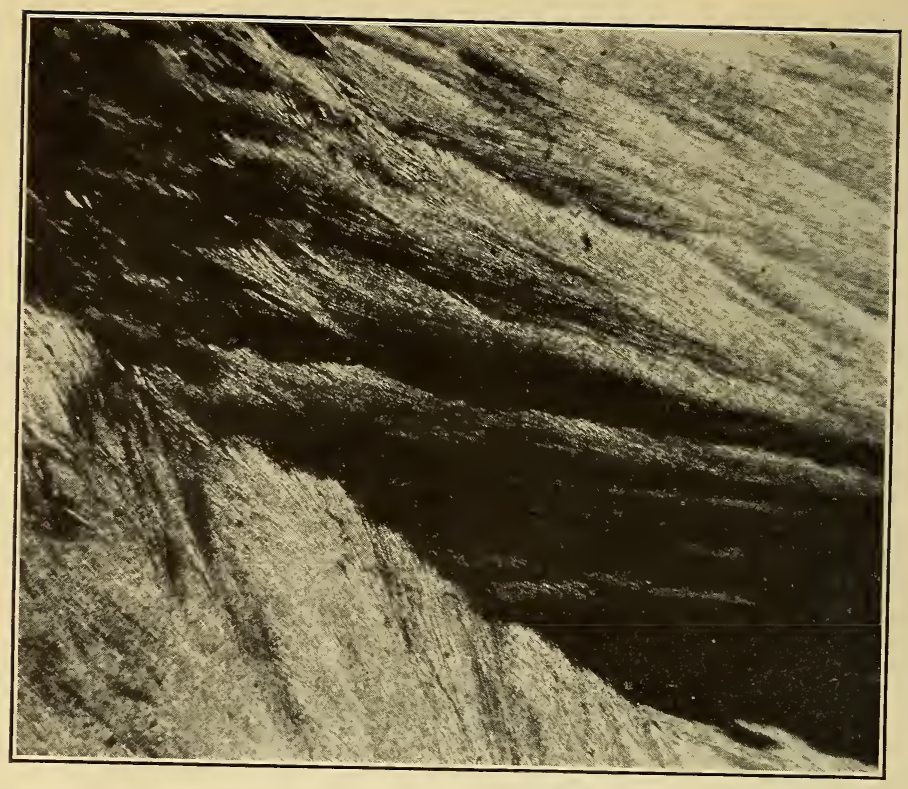

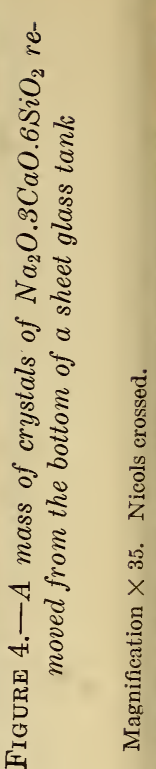

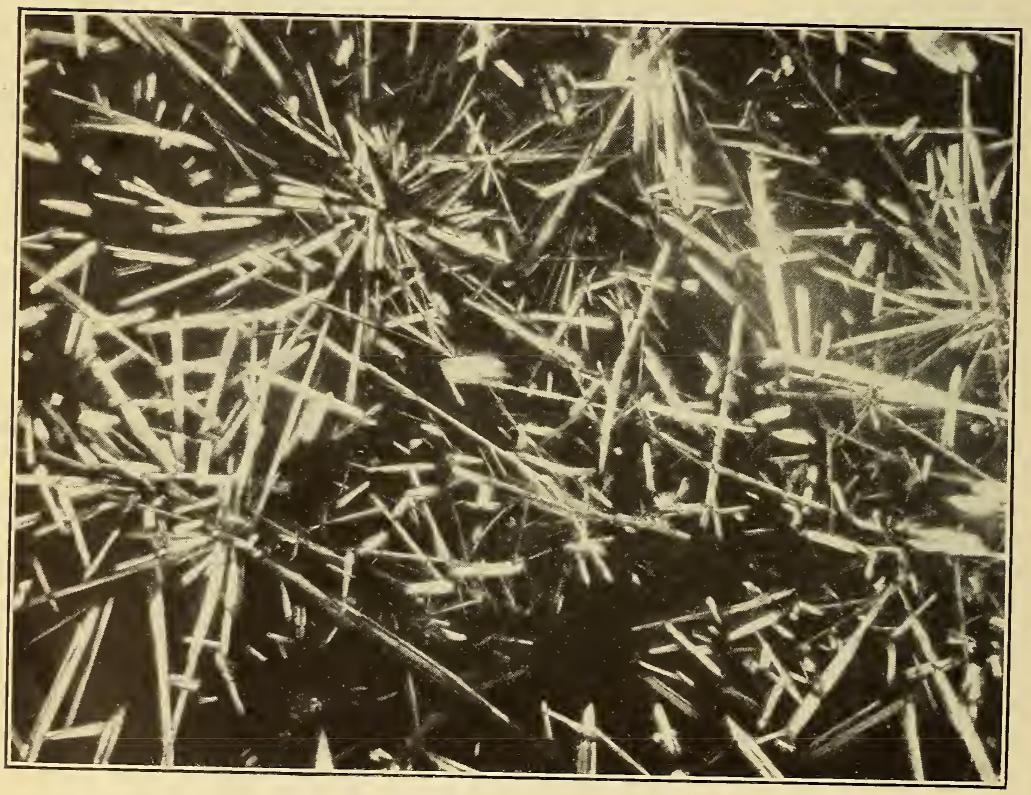

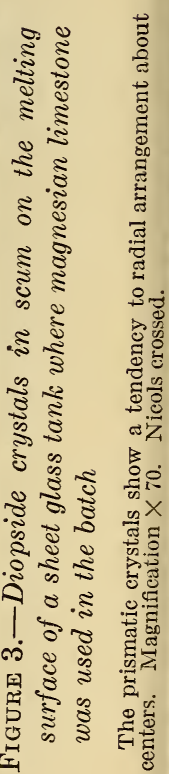


steps should be taken to eliminate it. The microscope offers little aid in this connection. Usually the only method possible is to trace the devitrification from the point at which it is first seen back toward the melting operation, taking samples frequently and systematically.

When devitrification takes place along cords in the glass, it is probably caused by a higher concentration of one constituent in the cord than in the adjacentglass. In this case elimination of the cords may stop the devitrification. Nonuniformity of the batch or entrainment and remelting of scum are known causes of cordiness.

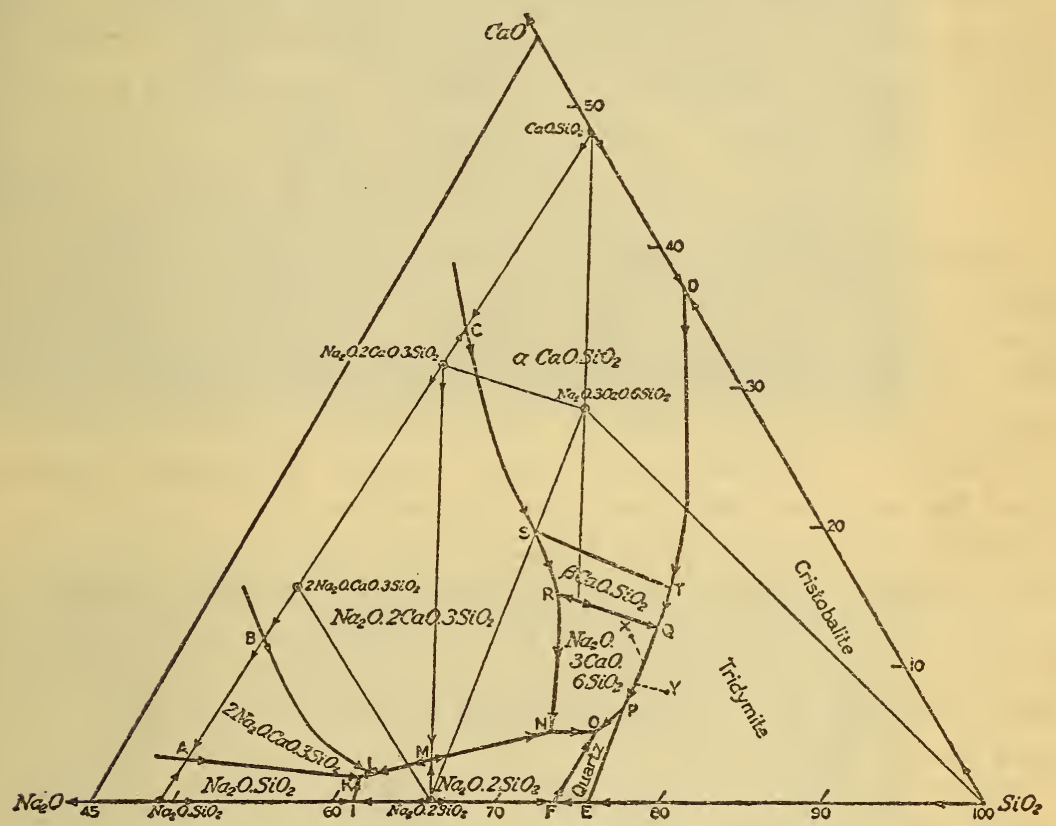

FIGURe 6.-Crystallization diagram of the system $\mathrm{Na}_{2} \mathrm{O} . \mathrm{SiO}_{2}-\mathrm{CaO}$. SiO ${ }_{2}-\mathrm{SiO}_{2}$

From Morey and Bowen, J. Soc. Glass Tech., 9, pp. 226-264; 1928, on a weight per cent basis. Arrows indicate directions of falling temperatures.

Random distribution of devitrification stones throughout a glass melt indicates either that the composition of the glass is too high in the constituents crystallizing or that the glass is allowed to remain too long at temperatures favorable to crystallization. In the sodalime-silica glasses containing only very small amounts of other oxides the nature of the compound crystallizing may be determined with the microscope and by reference to the equilibrium diagram of the system $\mathrm{Na}_{2} \mathrm{SiO}_{3}-\mathrm{Ca}_{3} \mathrm{SiO}_{2}-\mathrm{SiO}_{2}$ (fig. 6), ${ }^{2}$ the necessary direction of change of the glass composition can be determined. In general, the composition should be changed in the direction of falling temperatures indicated by arrows on the lines in Figure 6. For instance, the point

Morey and Bowen, J. Soc. Glass Tech., 9, pp. 226-262; 1925.

$47559^{\circ}-29-6$ 
$X$ (fig. 6) represents the composition of a window glass. If manufacturing conditions are such that this glass must be held at temperatures just below $1,000^{\circ}$ for some time, devitrification may take place with separation of crystals of $\mathrm{Na}_{2} \mathrm{O} .3 \mathrm{CaO} \cdot 6 \mathrm{SiO}_{2}$. By changing the composition of the glass from $X$ along the dotted line, the temperature at which crystallization takes place will be lowered and devitrification may be prevented. In the same way a bottle glass composition represented by the point $Y$ may be changed along the dotted line to prevent crystallization of tridymite. When change in composition is not feasible, devitrification may frequently be prevented by raising the temperature slightly at the place where crystals occur and allowing the glass to cool rapidly through temperatures favorable to crystallization further on in the glass-making process.

\section{BATCH STONES}

Batch stones are caused by the incomplete solution of one of the batch constituents. Undissolved sand is by far the most usual source of such stones, although other sources, such as lumps of lime and segregations of coloring constituents, have been found. The quartz composing the cores of batch stones may be converted to tridymite or cristobalite or it may remain unchanged depending upon the length of time it is in the high temperature zone of the tank. Figure 7 shows a section of a batch stone containing circular areas with centers composed of quartz and outer portions composed of wedge-shaped tridymite twins. The needles radiating from the circular areas are cross-sections of tridymite plates which crystallized from the highly siliceous glass in the vicinity of the partially dissolved sand grains.

Where clay is used as the source of alumina in glass, batch stones sometimes result because of coarse grinding or balling of the clay. Their microscopic characteristics will be discussed with those of tank block stones which they resemble.

Four possible means of prevention of batch stones are:

1. Finer grinding of the batch.

2. More intimate mixing of the batch constituents.

3. Higher melting temperatures.

4. Longer melting time.

The scum so frequently found on the surface of the glass near the bridge in the melting chamber of bottle-glass tanks is caused by a combination of undissolved sand, devitrification products in the resulting highly siliceous surface of the melt, and drops falling from the silica brick crown of the tank. Figure 8 shows the upper portion of such a scum, collected from the surface of the glass in a tank after a shutdown. Note the roughly circular areas filled with small tridymite twins and surrounded by platy crystals of tridymite. 


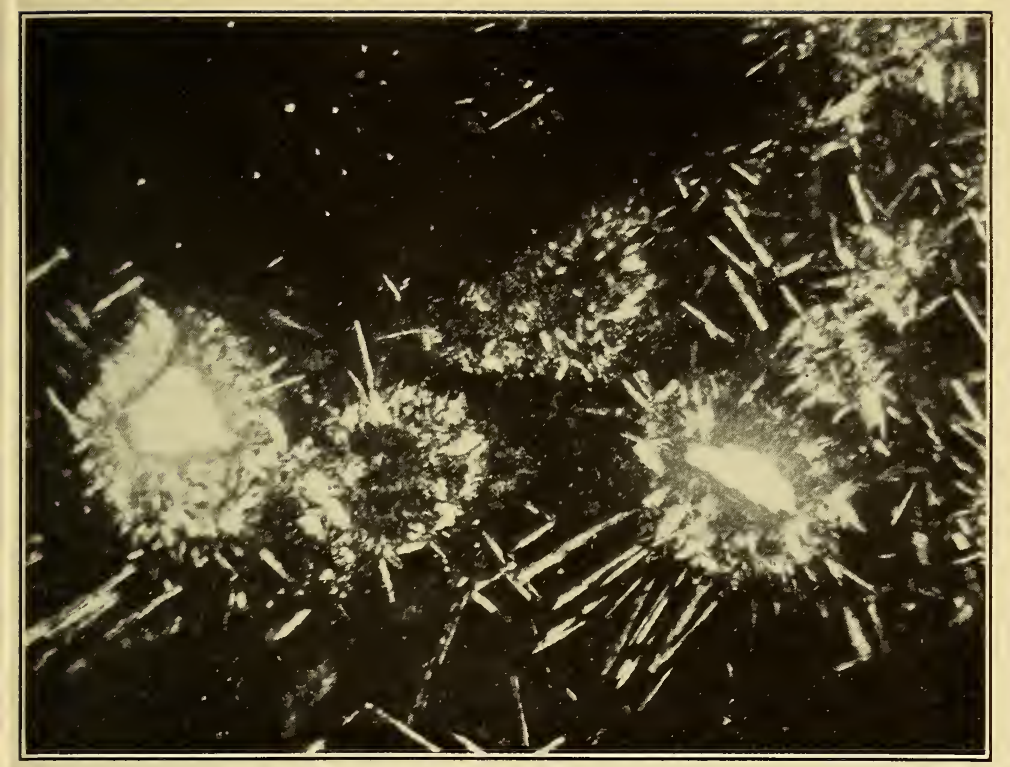

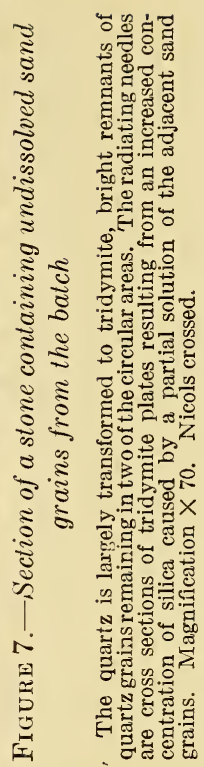

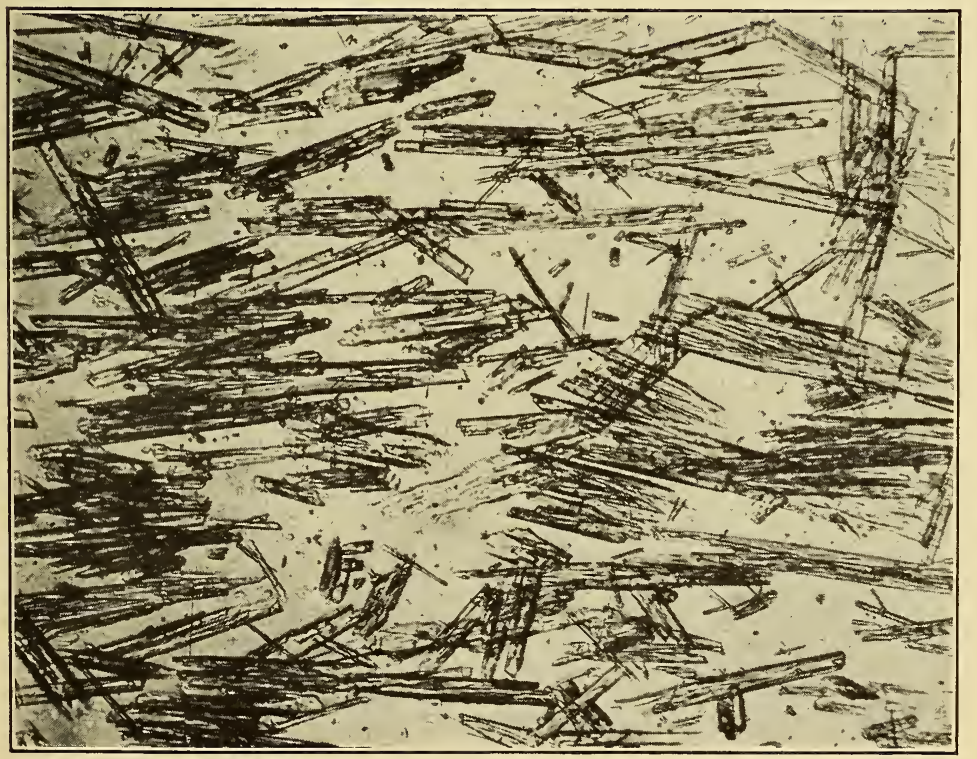

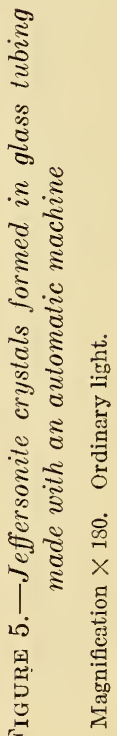




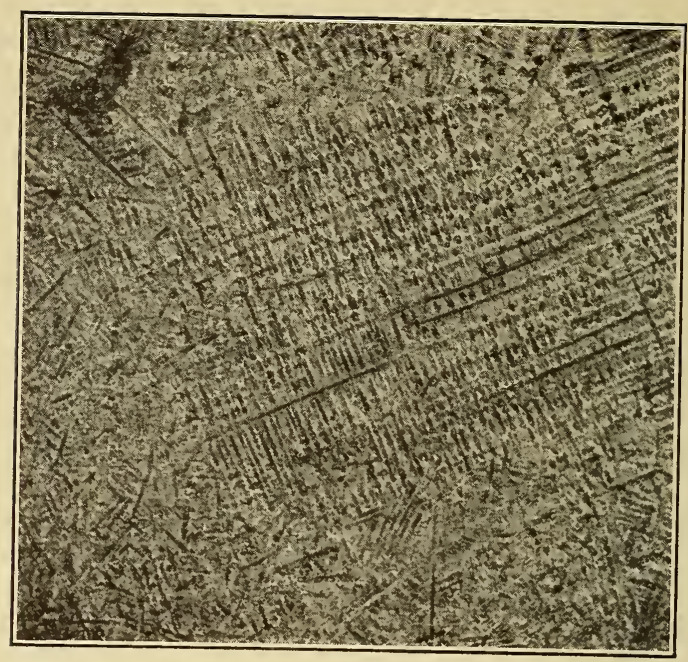

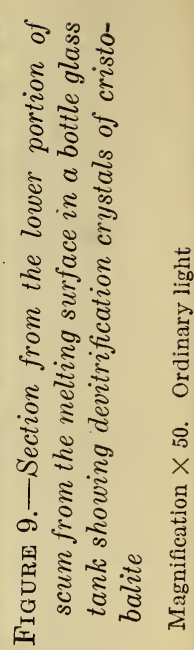

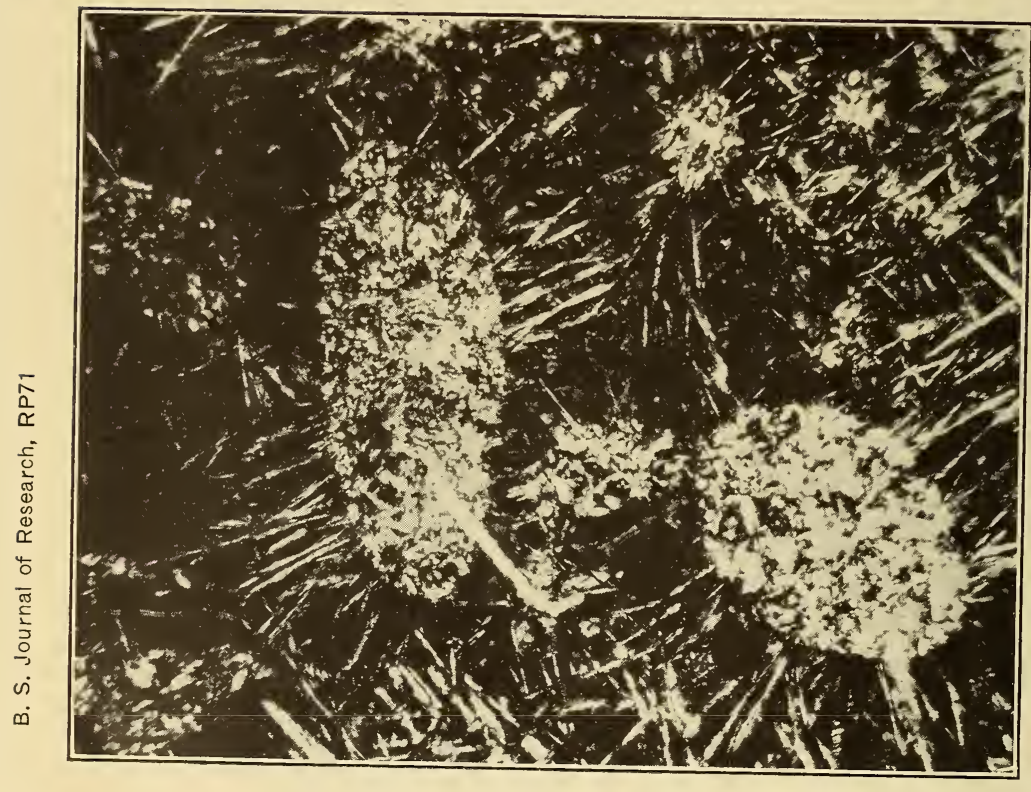

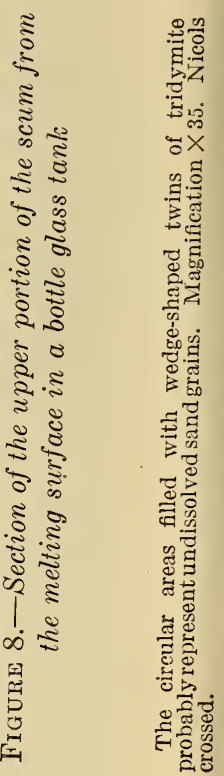


The formation of wedge-shaped tridymite twins is characteristic of the quartz to tridymite inversion, while the formation of plates is generally the result of crystallization from solution. The diameter of these roughly circular areas is only slightly less than that of sand grains usually used in the batch. A typical section of the lower portion of the scum is seen in Figure 9. Here the scum is composed almost entirely of cristobalite.

\section{REFRACTORY STONES}

Refractory stones are derived from the walls of the containing vessels in which the glass is made. These vessels may be the melting tank, the flow spouts, or the pots or tanks from which glass is fed to the machines.

Two general types of stones derived from clay refractories can be recognized: (1) Those from above, and (2) those from below the glass surface.

Clay walls above the surface of the glass are attacked by the volatilized soda in the furnace atmosphere and by batch dusts composed largely of soda and lime. In the high temperatures of the melting chamber, corundum $\left(\mathrm{Al}_{2} \mathrm{O}_{3}\right)$ and an alkali-aluminum-silicate liquid are the result of the reaction between the clay and the alkalies, ${ }^{3}$ unless the clay block is extremely siliceous, and then the liquid silicate may be the only product of the reaction. Where faces of the clay block slope in the appropriate direction, the liquid silicate may flow into the molten glass carrying the crystals of corundum. Since corundum is not easily soluble in molten glass, these crystals frequently persist in the finished glass as stones.

The reaction between clay blocks and molten soda-lime glass where they are in contact is similar to that between clay blocks and the alkaline atmosphere of the furnace. Apparently in both cases the effect of the alkali, and probably of the lime, is to lower very markedly the temperature at which aluminum silicates dissociate into corundum and liquid and to permit this dissociation to take place in compositions fairly high in silica. In the system containing only $\mathrm{Al}_{2} \mathrm{O}_{3}$ and $\mathrm{SiO}_{2}$ (fig. 10), mixtures with more than 55 per cent $\mathrm{Al}_{2} \mathrm{O}_{3}$ dissociate into corundum and liquid at $1,810^{\circ} \mathrm{C}$. under equilibrium conditions. Microscopic examination has shown ${ }^{4}$ that the dissociation into corundum and liquid takes place in burned clay in contact with soda-lime glass when the temperatures are those of commercial melting practice (below $1,550^{\circ}$ C.) and when the clay block contains less $\mathrm{Al}_{2} \mathrm{O}_{3}$ than the molecular ratio $\mathrm{Al}_{2} \mathrm{O}_{3} \cdot 2 \mathrm{SiO}_{2}$.

A small amount of molten soda-lime glass penetrating into the clay walls or into the clay stones floating in the glass acts as a flux 
which induces an increase in the size of the mullite $\left(3 \mathrm{Al}_{2} \mathrm{O}_{3} \cdot 2 \mathrm{SiO}_{2}\right)$ crystals. At the same time the siliceous liquid remaining after the formation of mullite from the clay diffuses into the soda-lime glass. Continued action may lower the dissociation temperature sufficiently to cause solution of the mullite and simultaneous crystallization of corundum; except, infrequently, when the clay block contains so much silica that corundum can not be formed and solution of the mullite leaves only liquid. The liquid developed by the crystallization and later dissociation of mullite may partially crystallize as nephelite $\left(\mathrm{Na}_{2} \mathrm{O} \cdot \mathrm{Al}_{2} \mathrm{O}_{3} \cdot 2 \mathrm{SiO}_{2}\right)$. The fact that nephelite so frequently occurs as skeleton crystals surrounding mullite or corundum suggests

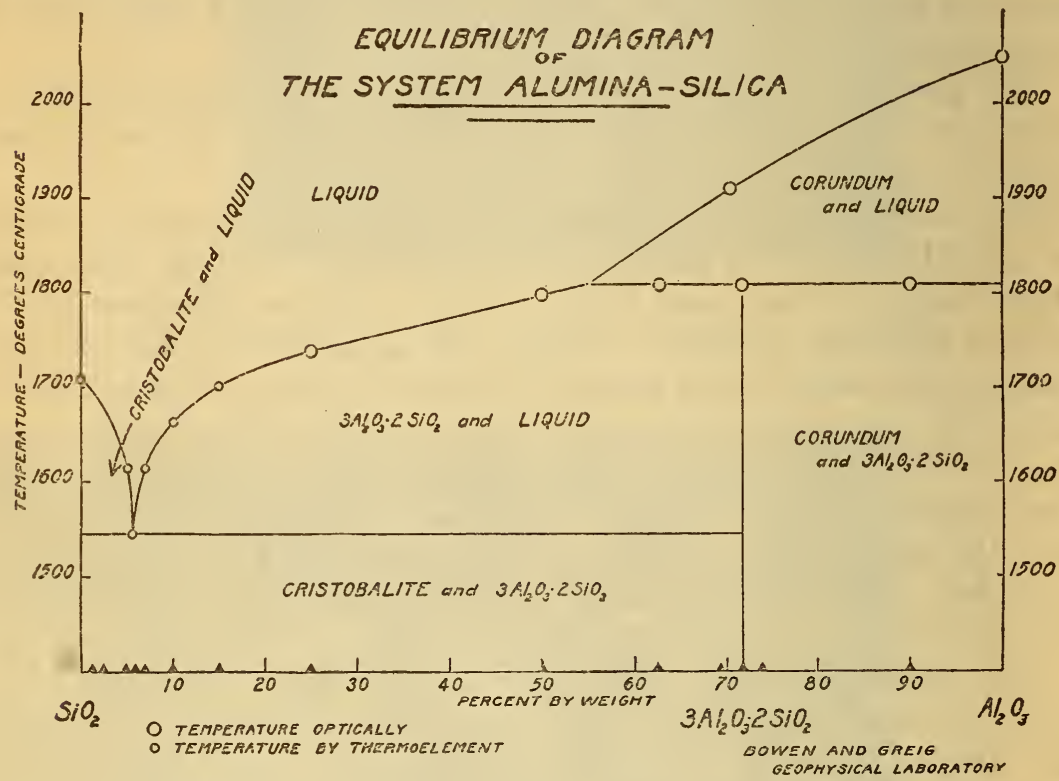

FIGURE 10.-Equilibrium diagram of the system $\mathrm{Al}_{2} \mathrm{O}_{3}-\mathrm{SiO}_{2}$

From Bowen and Greig, J. Amer. Cer. Soc., 7, p 242; 1924.

that it forms during the cooling of the glass and not while it is at maximum temperatures.

The location of the source of refractory stones may be approximately determined from the size and nature of the crystals in them. Stones from blocks above the glass line usually are composed only of corundum. (Fig. 11.) Sometimes nephelite is present; and, rarely, large mullite crystals. The corundum crystals are always relatively large (more than $0.5 \mathrm{~mm}$ in width). A stone in which even the corundum has disappeared and only the reaction product (nephelite) remains is shown in Figure 12. Stones from tank blocks below the glass line in the hotter parts of the tank and clay stones from the batch are made up largely of corundum crystals with well-developed 


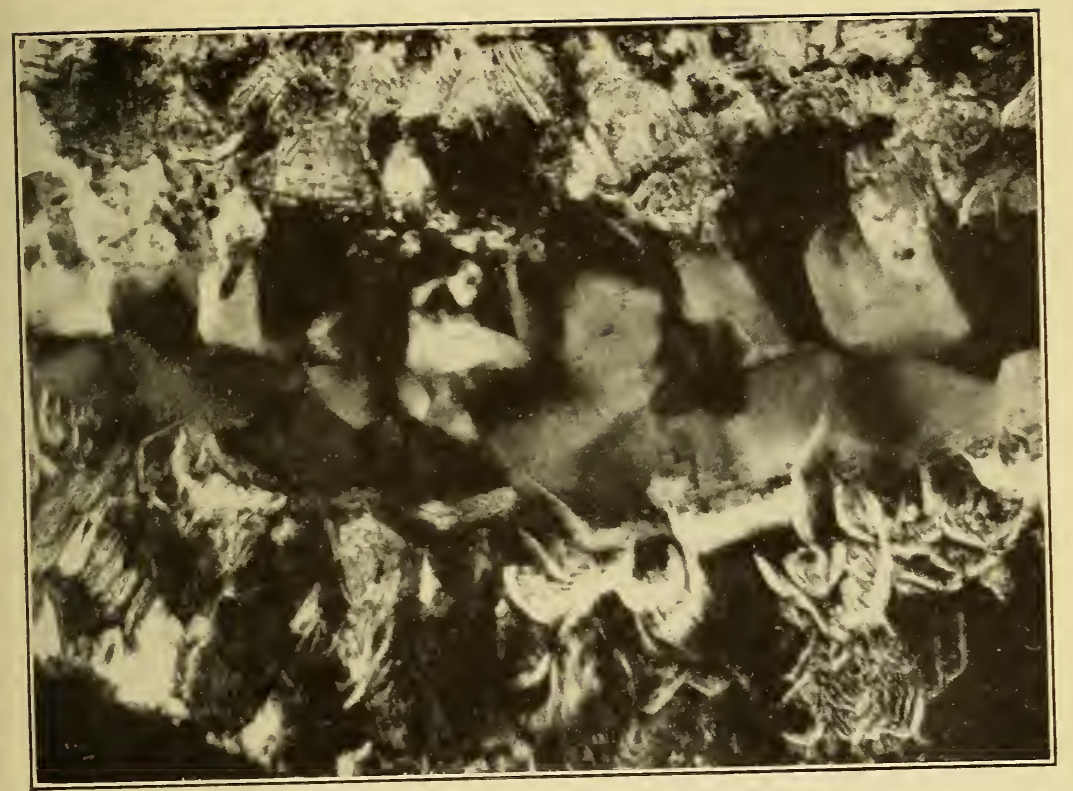

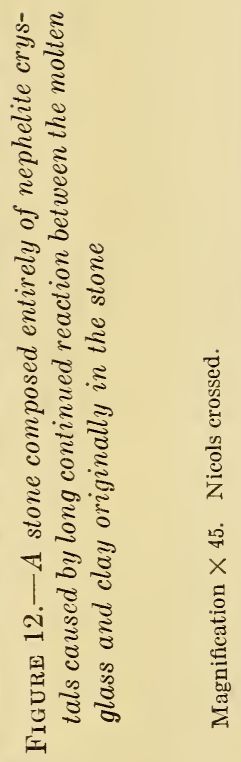

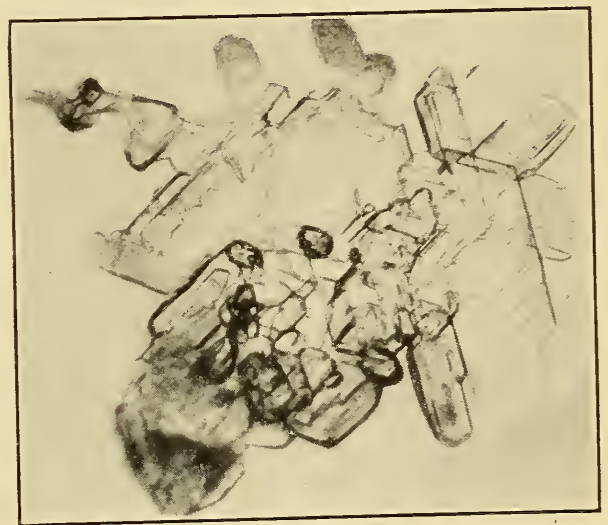

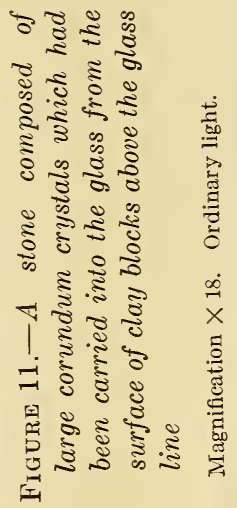




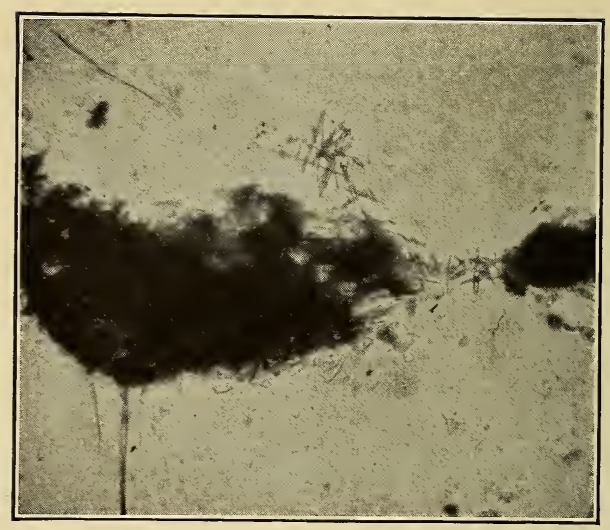

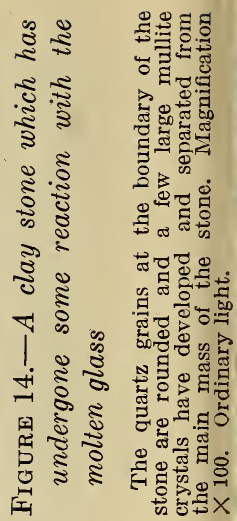

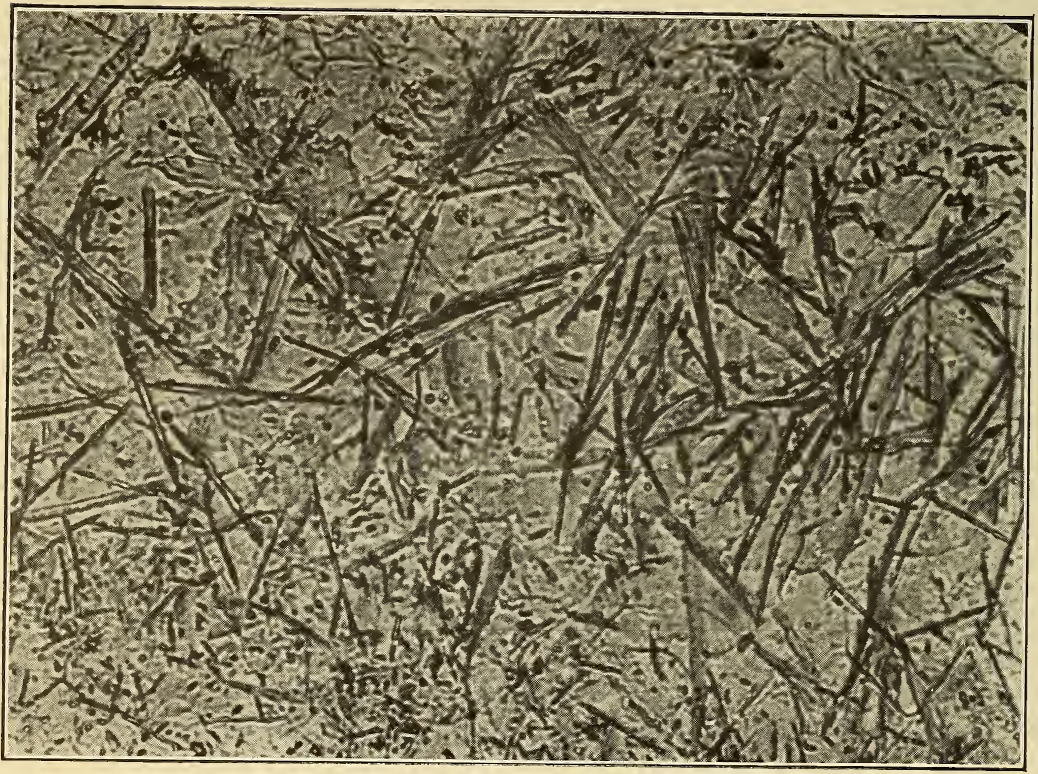

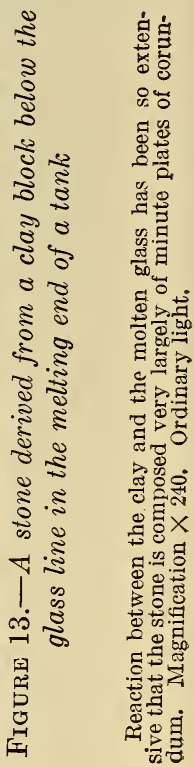


B. S. Journal of Research, RP71

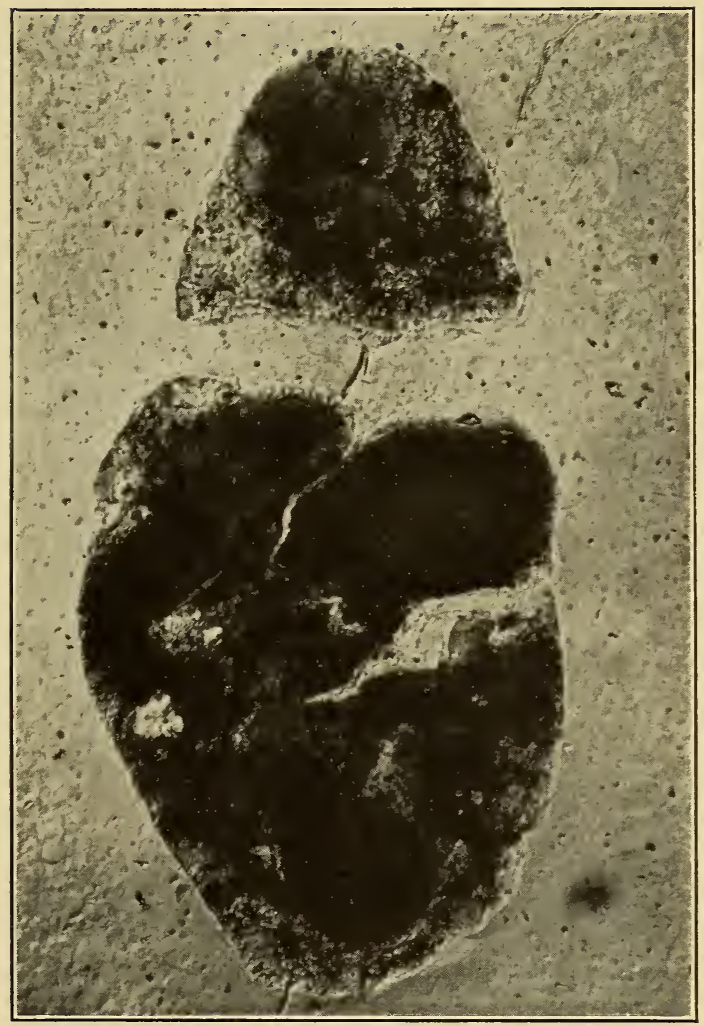

Figure 15.-A clay stone which has undergone very little reaction with the molten glass

Magnification $\times 160$. Ordinary light. 
mullite needles sometimes present. The corundum crystals from blocks below the glass line are always smaller than those from tank blocks above the glass line and are frequently very minute. (Fig. 13.) If the clay contained quartz grains originally, these are usually completely dissolved. In general, the crystals in such stones are not aggregated, but are somewhat dispersed. Nephelite is frequently associated with the corundum.

Stones from blocks in such cooler parts of the system as the refining end of the melting tank, the flow spouts, and the machine-feeding pots and tanks show much less reaction with the molten glass. A few minute corundum crystals may be found at the outer border of the stone, and quartz grains in the clay frequently remain undissolved. Mullite crystals may be large or small, but generally are in closepacked masses and show little tendency to be separated from the main mass of the stone except at the outer edge. Figure 14 shows a stone in which a small amount of reaction and solution has taken place. The quartz grains at the outer border of the stone are rounded and partially dissolved, and a few large mullite needles have developed and floated away in the glass. The stone shown in Figure 15 has been very little affected by the molten glass. Sharp corners have been rounded off, but no crystalline reaction products have been formed.

In melting operations using a batch containing clay there seems to be no microscopic method of distinguishing between clay stones from this source and stones given off by refractory blocks in the melting end of the tank. Both are very similar in microscopic appearance and in crystalline compounds formed. Once having determined with the microscope that the stones came from either of these two sources, a knowledge of the condition of the tank refractories and of the way the batch is mixed and ground must be relied on to make the distinction.

Microscopic examination of tank-block stones gives evidence of their point of origin in the glass-making system, but it gives no information as to how such stones may be eliminated. Usually either the offending blocks are replaced or they are backed with some sort of cooling arrangement.

Stones from blocks above the glass line are particularly annoying, since large crystals of corundum dissolve very slowly in molten glass. The greater the height to which clay walls extend above the glass line, the greater the danger from these highly insoluble stones. In designing tanks, consideration should be given to the advantages of eliminating clay blocks above the glass line on the side walls, the end of the melting chamber, and the bridge wall. 


\section{SUMMARY}

The petrographic microscope affords a means of distinguishing between devitrification, batch, and refractory stones. Compounds crystallizing as devitrification stones are described and a method of determining the proper changes in temperature or composition of the melt to eliminate them is given. The characteristics of batch stones are enumerated and better grinding and mixing of the batch are suggested as means of prevention of this type of stone. The degree of reaction of refractory stones with the molten glass and the crystalline compounds formed are discussed; and they may be used as a means of determining the approximate location of the source of such stones.

Washington, January 2, 1929. 